\title{
5-HTTLPR and Gender Moderate Changes in Negative Affect Responses to Tryptophan Infusion
}

\author{
Beverly H. Brummett $\cdot$ Christopher L. Muller · Ann L. Collins · \\ Stephen H. Boyle • Cynthia M. Kuhn · Ilene C. Siegler • \\ Redford B. Williams · Allison Ashley-Koch
}

Received: 13 May 2008/ Accepted: 16 July 2008/Published online: 26 July 2008

(C) Springer Science+Business Media, LLC 2008

\begin{abstract}
Expression of the serotonin transporter is affected by the genotype of the 5-HTTLPR (short and long forms) as well as the genotype of the SNP rs25531 within this region. Based on the combined genotypes for these polymorphisms, we designated each allele as a high or low expressing allele according to established expression levels-resulting in HiHi, HiLo, \& LoLo genotype groups for analysis. We evaluated effects of gender and the promoter genotype on induction of negative affect by intravenous infusion of L-tryptophan (TRP). The protocol consisted of a day-1 sham saline infusion and a day- 2 active TRP infusion. Models assessed 5-HTTLPR composite genotype and gender as predictors of change in ratings of negative emotion during TRP infusion. During sham infusion there were no significant changes from baseline in mood ratings. During TRP infusion all negative affect ratings increased significantly from baseline $(P$ 's $<.02)$. The genotype $\times$ gender interaction was a significant predictor of
\end{abstract}

Edited by Tatiana Foroud.

Portions of this manuscript were presented at the citation poster session of the 2008 meeting of the American Psychosomatic Society, Baltimore, MD.

B. H. Brummett $(\bowtie) \cdot$ S. H. Boyle · I. C. Siegler ·

R. B. Williams

Department of Psychiatry and Behavioral Sciences, Duke University Medical Center, Box 2969, Durham, NC 27710, USA

e-mail: brummett@duke.edu

C. L. Muller · A. L. Collins · A. Ashley-Koch

Center for Human Genetics, Duke University Medical Center,

Durham, NC 27710, USA

C. M. Kuhn

Department of Pharmacology and Cancer Biology, Duke

University Medical Center, Durham, NC, USA depression-dejection $(P=.013)$, and trended towards predicting anger-hostility $(P=.084)$. Males in the HiHi group had greater increases in negative affect during infusion, compared to all groups except LoLo females, who also showed increased negative affect.

Keywords 5-HTTLPR · Gender · L-tryptophan . Mood $\cdot$ Serotonin $\cdot$ SNP rs25531

\section{Introduction}

An extensive literature, using increased blood prolactin levels as an index of central nervous system (CNS) serotonin function, documents that intravenous infusion of the serotonin precursor L-tryptophan (TRP) increases central serotonin (5-HT) function (Checkley 1980; Price et al. 1990; Yatham and Steiner 1993). The theory that individual differences in CNS 5-HT function account for differences in disposition has been widely examined using neuroendocrine challenge protocols that alter CNS serotonin activity (e.g., intravenous infusion of TRP and oral fenfluramine). Challenge studies have demonstrated associations among emotionally related behavioral traits and central serotonergic activity (e.g., Cleare and Bond 1995; Cleare and Bond 1997; Coccaro 1992; Coccaro et al. 1989; Marsh et al. 2002; Moeller et al. 1994; O'Keane et al. 1992). Findings from challenge protocols that enhance CNS 5-HT neurotransmission have also documented that gender differences exist with respect to associations among serotonergic activity and personality traits. For example, neuroticism has been negatively related to prolactin response to a fenfluramine challenge, but only for males (Manuck et al. 1998). In addition to demonstrations of associations among personality traits and CNS serotonin 
function, transient changes in mood have been assessed during serotonin enhancement protocols. Assessments of mood during TRP infusion in healthy samples has generally shown worsening of affect, and/or increased feelings related to lack of energy (Cowen and Charig 1987; Heninger et al. 1984; Price et al. 1991).

A related body of literature indicates that the serotonin system in men and women may behave quite differently in important ways. One study using positron emission tomography has shown that in males the rates of central nervous system (CNS) serotonin synthesis are approximately 50\% higher than in females (Nishizawa et al. 1997). Conversely two studies using a different index of CNS 5-HT have shown that cerebrospinal fluid (CSF) levels of the major serotonin metabolite 5 HIAA are higher in women than in men (Jonsson et al. 2000; Williams et al. 2003). Moreover, $5 \mathrm{HT}_{\mathrm{A}}$ and $5 \mathrm{HT}_{2}$ receptor density is lower in the brains of women than men (Biver et al. 1996; Costes et al. 2005) and selective serotonin re-uptake inhibitors (SSRI) have greater efficacy in women, as compared to men (Kornstein et al. 2000). As previously noted, individual differences in CNS 5-HT function are thought to account for differences in disposition and research findings in this area also suggests that the serotonin transporter gene promoter polymorphism (5-HTTLPR) genotype may have an opposite effect on behavioral characteristics in men and women. In some studies, the presence of the L allele has been associated with higher levels of depressive symptoms and/or negative affect in males, whereas, in females it is those carrying the $\mathrm{S}$ allele who exhibit such symptoms (Brummett et al. 2008, 2003; Eley et al. 2004; Flory et al. 1999; Gonda et al. 2005; Jacobs et al. 2006; Sjoberg et al. 2006; Surtees et al. 2006). However, some findings in related constructs are in the opposite direction. Specifically, higher levels of neuroticism (Du et al. 2000) and harm avoidance (Gelernter et al. 1998) have been associated with the s allele, but in males only. One potential confounder to some of these results is that the activity of the short (S) and long (L) alleles of the 5-HTTLPR has been shown to be modified by a single nucleotide polymorphism (SNP) within the region (rs25531) (Hu et al. 2006), which has not frequently been analyzed in the past. Thus, the topic of gender and genotype on negative effects clearly merits further investigation including more careful examination with respect to the categorization of serotonin transporter alleles.

In the present study we analyzed negative affective responses assessed during a TRP enhancement challenge that consisted of a day- 1 sham saline infusion and a day- 2 active TRP infusion. Building on the above research that indicates allelic variation in 5-HTTLPR may have an opposite effect on behavioral characteristics in men and women and that results of challenge protocols have shown gender differences in associations among CNS serotonergic activity and mood, we included examination of gender and genetic variation in the serotonin polymorphism 5-HTTLPR as predictors of emotional responding to a TRP challenge. We included examination of the A/G SNP (rs25531) that modifies the activity of the insertion/deletion polymorphism, resulting in a multiallelic marker for which the most common alleles are $\mathrm{L}_{\mathrm{G}}, \mathrm{L}_{\mathrm{A}}$, and $\mathrm{S}$ (Hu et al. 2006). Previously, $\mathrm{L}_{\mathrm{G}}$ and $\mathrm{S}$ alleles were shown to be associated with comparably lower transcriptional activity relative to the $\mathrm{L}_{\mathrm{A}}$ allele $(\mathrm{Hu}$ et al. 2006). Therefore, for our analyses composite alleles were categorized according to transcriptional activity $\left(\mathrm{L}_{\mathrm{A}}\right.$ as $\mathrm{Hi}$, and $\mathrm{L}_{\mathrm{G}} \& \mathrm{~S}$ as $\mathrm{Lo}$ ); resulting in 3 genotype groups $(\mathrm{HiHi}$, HiLo, \& LoLo). Regression models were used to assess these 5-HTTLPR genotype groups and gender as moderators of change in ratings of negative emotion during sham and active TRP infusion.

\section{Methods}

\section{Participants}

Participants were invited to take part in a study designed to examine the moderating effects of genetic, behavioral, and environmental mechanisms on health disparities. Recruitment took place from 1998 to 2003 and consisted of advertisements in the public media, inclusion in the community newsletter sent with the county water bill, flyers posted throughout the community, outreach screening events at civic organizations and other public events, and paid advertisements such as the back of supermarket tapes. The study was conducted at Duke University Medical Center and all subjects gave informed consent prior to their participation in the study using a form approved by the Duke University Medical Center Institutional Review Board. Those enrolled in the study received $\$ 500$ for their participation. The study protocol required that participants be in good current health because of the study procedures, (see below) (Williams et al. 2001, 2003) and; therefore, all participants underwent a comprehensive psychological examination, as well as medical history, physical exam, electrocardiogram, chest radiograph, hemoglobin, hematocrit, white cell count, and blood chemistries to rule out current medical and psychiatric disorders (including depression). Use of any prescription drugs as well as use of illegal drugs (as detected by a urine screen prior to entry into study) were grounds for exclusion (Burroughs et al. 2003). The study sample consisted of 80 participants and it was later found that 1 participant did not meet inclusion criteria. Of the remaining 79 individuals, 7 did not have data for genotype or affect assessment during the protocol, resulting in 72 participants (31 females and 41 males) who are the focus of the present study. 


\section{Procedure}

Upon evening admission to the Clinical Research Unit at Duke University Medical Center, sociodemographic and personality data were gathered, and blood was drawn for assessment of biological parameters. Test day one consisted of a sham TRP infusion using saline (see Williams et al. 2001), and test day two consisted of an active TRP infusion. With the exception of administration of either the active or sham TRP infusion, the protocol for days 1 and 2 were identical.

\section{Tryptophan challenge protocol}

On the day of the active TRP infusion, beginning at 6:30 a.m. participants were not allowed food or liquids, nor were they allowed to smoke, until the completion of all study procedures at approximately 1:30 p.m. At 7:00 a.m. an IV (D5W/0.5 N saline) was started and kept running at $50 \mathrm{cc}$ per hour till 1:30 p.m. All participants were seated in a reclined position and activity was limited to watching nature videos provided by the investigator or playing cards. Bathroom visits were allowed up to the time of tryptophan infusion. At 11:00 a.m. participants received either a full dose of TRP (100 mg/kg body weight) or saline over a period lasting $25 \mathrm{~min}$. A blood pressure cuff was placed around the infusion bag and inflated up to a maximum of $35 \mathrm{mmHg}$ if needed to complete the total dose within $25 \mathrm{~min}$. At the end of the infusion, the IV was returned to D5W/0.5 N saline. The challenge protocol was carried out under single-blind conditions, with participants unaware of condition.

\section{Affect assessment}

Negative emotional states were assessed using the Profile of Mood States (POMS) (McNair and Lorr 1964). Affect was assessed prior to infusion (baseline) and again 1 hour post the start of infusion, for both sham and active days. The POMS consists of affective items (rated $0=$ not at all to 4 = extremely) which may be summarized, creating 4 scales that represent the negative affect dimensions of: anger-hostility, depression-dejection, fatigue-inertia, and tension-anxiety. The POMS has been frequently used to examine mood change during challenge studies (Richell et al. 2005; Van der Does 2001), and has acceptable validity and reliability (Knapp et al. 1998).

\section{Genotyping}

The promoter region surrounding the 5-HTTLPR and rs25531 polymorphisms was amplified and used to create a composite genotype reflecting the alleles of both polymorphisms. PCR of the promoter region was performed in a $25-\mu$ l volume with $30 \mathrm{ng}$ DNA, $1 \times$ PCR Buffer (Invitrogen $10 \times$ PCR Buffer); $1.5 \mathrm{mM} \mathrm{MgCl}_{2}$ (Invitrogen $50 \mathrm{mM} \mathrm{MgCl} 2) ; 0.2 \mathrm{mM}$ each of dATP, dCTP, and dTTP; $0.1 \mathrm{mM}$ dGTP; $0.1 \mathrm{mM} 7$-deaza dGTP; $4 \mathrm{ng} / \mu \mathrm{l}$ of each primer; $0.03 \mathrm{U} / \mu \mathrm{l}$ Platinum Taq DNA polymerase; and $7.5 \%$ DMSO. The forward primer was 5'FAMGGCGTTGCCGCTCTGAATGC-3', and the reverse primer was $5^{\prime}$-AGGGACTGAGCTGGACAACCAC- $3^{\prime}$. The DNA was denatured at $95^{\circ} \mathrm{C}$ for $5 \mathrm{~min}$. For 37 cycles, the DNA was denatured at $95^{\circ} \mathrm{C}$ for $30 \mathrm{~s}$, annealed at $61^{\circ} \mathrm{C}$ for $30 \mathrm{~s}$, and extended at $72^{\circ} \mathrm{C}$ for $1 \mathrm{~min}$. PCR was terminated by an extension at $72^{\circ} \mathrm{C}$ for $5 \mathrm{~min}$. The PCR product was purified by adding $5 \mu \mathrm{l}$ of SOPE resin (Edge Biosystems) to the product and eluting the mixture through a sephadex column. $1 \mu \mathrm{l}$ of the purified PCR product was diluted in $24 \mu \mathrm{l}$ of $\mathrm{dH}_{2} \mathrm{O}$ for 5-HTTLPR genotyping. The rest of the purified product was kept for genotyping the SNP (rs25531) within the insertion/deletion.

The 5-HTTLPR marker was genotyped by size separation of the PCR fragment on the 3730 DNA Analyzer (Applied Biosystems). The PCR products were sized utilizing the 1200LIZ size standard (Applied Biosystems) which captures the rare extra long (XL) allele as well as the standard long (L) and short (S) alleles associated with this marker. The raw data was examined in GeneMapper (Applied Biosystems) to determine the alleles for each sample.

The rs25531 marker was genotyped by digesting the PCR product with HpaII, a restriction enzyme that cuts at the SNP site only if the $G$ allele is present. The digestion was cleaned with sephadex and the fragments were size separated on a 3730 DNA Analyzer using the 500LIZ Size Standard (Applied Biosystems). Of the resulting fragments from the digestion, only those from the FAM labeled end of the PCR product can be detected on the 3730. The raw data was examined in GeneMapper to determine the alleles for each sample. The $\mathrm{L}_{\mathrm{A}}$ allele peak was detected at $332 \mathrm{bp}$; the $\mathrm{L}_{\mathrm{G}}$ allele peak was detected at $162 \mathrm{bp}$; and the $\mathrm{S}_{\mathrm{A}}$ allele peak was detected at $289 \mathrm{bp}$. Theoretically, if a Sg were present it would also be detected as it would present as a short allele in the 5-HTTLPR size separation, but run with the $\mathrm{Lg}$ in the rs25531 genotyping. However, we did not identify any $\mathrm{Sg}$ alleles, suggesting these alleles are rare. Therefore, genotypes designated $\mathrm{S}$ are technically $\mathrm{S}_{\mathrm{A}}$. Size estimation from Genemapper is not exact. However, these sizes were consistent with the theoretical fragment sizes calculated using HpaII to digest the PCR product.

The resulting genotypes from both procedures were used to create a composite genotype reflecting $\mathrm{S}, \mathrm{La}, \mathrm{Lg}$, and XL alleles. These genotypes were then categorized as high or low expressing based on previous literature. The XL alleles were categorized with the $\mathrm{L}_{\mathrm{A}}$ as $\mathrm{Hi}$ expressing.

Additional quality control for all genotyping consisted of duplicate DNA's placed throughout the DNA plates in 
which $100 \%$ matching results were required. Laboratory technicians were blinded to the matching pattern of these duplicates. We also required greater than $95 \%$ efficiency on each genotyping protocol, i.e., no more than $5 \%$ of the samples processed could fail the assay.

This modified genotyping approach has several advantages over previous genotyping protocols for these polymorphisms. While many protocols have used this primer set to obtain the 5-HTTLPR polymorphism, the current approach utilizes the same PCR product for genotyping the rs25531 polymorphism. Consequently, the presence of additional HpaII sites in the PCR product allow for differentiation between heterozygosity of rs25531 and partial digestion. This provides reliable high-throughput genotyping without need for exact quantification of PCR product prior to digestion. Additionally, use of a capillary sequencer for size separation also increased throughput and automation over running the digest on agarose gels. By utilizing the dual genotyping methods, we were able to identify the XL alleles that were previously difficult to identify after digestion, to verify that no Sg alleles were present, as well as to provide some additional quality control for determining alleles, as the calls for short or long alleles must be consistent between the two genotyping methods.

\section{Analysis}

For sham and active infusion days, change scores were created for the 4 negative affect dimensions by subtracting the pre-infusion (baseline) rating from the post-infusion rating for each affect dimension. Paired $t$-tests were conducted on these change scores to assess whether or not affect ratings changed significantly from pre-TRP to postTRP infusion. In linear regression models, gender and 5-HTTLPR were used to predict change in the affect summary scores for anger-hostility, depression-dejection, fatigue-inertia, and tension-anxiety. Regression models were adjusted for baseline affect and race. Each initial model included a term representing gender, genotype (HiHi, HiLo, or LoLo transcriptional activity), race (Caucasian or African American), and the baseline affect rating; along with a gender $\times$ genotype interaction term allowing us to examine moderation by these two factors. Nonsignificant interaction terms were then removed prior to final examination of main effects.

\section{Results}

Demographic characteristics

With respect to ethnicity, $39(54.2 \%)$ of the participants were African American and the remaining 33 (45.8\%) were
Caucasian. The average participant was 33.5 (S.D, 9.1) years old. Genotype classification of transcriptional activity was distributed as follows: $\mathrm{HiHi}=26 \quad(36.1 \%)$; HiLo $=30(41.7 \%) ;$ LoLo $=16(22.2 \%)$.

Primary analyses

TRP infusion significantly modified all negative affect ratings from baseline whereas sham infusion did not. Table 1 provides the POMS means for each affect at baseline, post-infusion, and the change for each POMS rating for both sham and TRP infusion days. Next we analyzed the effect of gender and genotype on change in the four affect types, adjusted for baseline and race. Neither gender nor genotype were found individually to display significant differences on negative affects. However, the interaction of genotype and gender was a statistically significant predictor of change in depression-dejection $(P=.013)$. This interaction was a nonsignificant predictor for fatigue-inertia, tension-anxiety, and anger-hostility, although anger-hostility did show a trend $(P=.084)$. The change in depression-dejection scores by genotype and gender are provided in Table 2 and graphically depicted in Fig. 1. Table 3 presents the results of the regression analysis for depression-dejection scores. Males in the HiHi genotype group had significantly greater increases in depression-dejection ratings affect during infusion, compared to all groups except LoLo genotype females. LoLo genotype females also showed significant increases in depression-dejection from baseline to post-infusion ratings. None of the remaining group comparisons were significantly different from one another. The pattern of change for anger-hostility was similar to that of depression-dejection.

Table 1 POMS baseline and post infusion values for sham (day 1) and TRP (day 2) infusion

\begin{tabular}{|c|c|c|c|}
\hline $\begin{array}{l}\text { POMS affect, means } \\
\text { (SEM) }\end{array}$ & Baseline & $\begin{array}{l}\text { Post- } \\
\text { infusion }\end{array}$ & Change, $P$-value \\
\hline \multicolumn{4}{|l|}{ Sham infusion-day 1} \\
\hline Anger-hostility & $1.3(0.3)$ & $1.9(0.5)$ & $0.60(0.3), 0.070$ \\
\hline $\begin{array}{l}\text { Depression- } \\
\text { dejection }\end{array}$ & $3.4(0.5)$ & $3.5(0.6)$ & $0.12(0.4), 0.779$ \\
\hline Fatigue-inertia & $3.4(0.4)$ & $3.4(0.4)$ & $-0.01(0.3), 0.966$ \\
\hline Tension-anxiety & $4.5(0.4)$ & $5.0(0.6)$ & $0.55(0.5), 0.261$ \\
\hline \multicolumn{4}{|l|}{ TRP infusion-day 2} \\
\hline Anger-hostility & $1.5(0.5)$ & $2.8(0.8)$ & $1.3(0.5), 0.018$ \\
\hline $\begin{array}{c}\text { Depression- } \\
\text { dejection }\end{array}$ & $3.0(0.6)$ & $5.2(1.0)$ & $2.2(0.7), 0.003$ \\
\hline Fatigue-inertia & $4.4(0.3)$ & $6.5(0.5)$ & $2.1(0.5), 0.001$ \\
\hline Tension-anxiety & $3.8(0.5)$ & $6.1(0.5)$ & $2.3(0.5), 0.001$ \\
\hline
\end{tabular}

Note: $P$-values are those associated with paired $t$-tests for baseline to post-infusion change 
Table 2 Mean change scores for depression-dejection, by gender and genotype

\begin{tabular}{lllll}
\hline Group & Baseline & $\begin{array}{l}\text { Post-TRP } \\
\text { infusion }\end{array}$ & $\begin{array}{l}\text { Mean } \\
\text { change }\end{array}$ & $P$-value \\
\hline Male HiHi $(n=15)$ & $3.2(1.7)$ & $9.4(3.0)$ & $6.2(2.3)$ & 0.019 \\
Male HiLo $(n=19)$ & $2.7(1.0)$ & $4.2(1.5)$ & $1.5(0.8)$ & 0.080 \\
Male LoLo $(n=7)$ & $2.9(1.7)$ & $1.5(0.7)$ & $-1.4(1.8)$ & 0.450 \\
Female HiHi $(n=11)$ & $5.2(2.4)$ & $5.6(1.9)$ & $0.4(1.9)$ & 0.849 \\
Female HiLo $(n=11)$ & $1.4(0.5)$ & $3.2(1.3)$ & $1.8(1.3)$ & 0.183 \\
Female LoLo $(n=9)$ & $2.8(2.1)$ & $5.4(2.9)$ & $2.6(1.1)$ & 0.050
\end{tabular}

Note: Mean change values are unadjusted, and $P$-values are those associated with paired $t$-tests for pre-TRP to post-TRP infusion change

No significant differences were found in negative affects based on gender or genotype alone.

On sham day-1 none of the product interaction terms for genotype $\times$ gender, nor their main effects, were significant predictors of any of the four negative affect change scores.

\section{Discussion}

To our knowledge this is the first study to examine both gender and functional variation in 5-HTTLPR as predictors of negative emotional reactions to an acute TRP infusion in a non-clinical sample. Importantly, the current pattern of results complements prior research that suggests for chronically stressed males the presence of 5-HTTLPR alleles that convey increased transcriptional activity may be associated with increased depressive symptoms. More broadly, the findings contribute to an existing literature indicating that, in males as compared to females, the serotonin system functions differently in ways that have implications for emotional wellbeing.

Apart from inclusion of a healthy control group for comparison purposes, emotional response to TRP infusion
Table 3 Regression analysis for POMS depression-dejection scores following TRP infusion

\begin{tabular}{lcc}
\hline Source & $F$-value $(\mathrm{df})$ & $P$-value \\
\hline Baseline depression-dejection rating & $82.7(1)$ & 0.001 \\
Race (African American, Caucasian) & $2.6(1)$ & 0.111 \\
Gender & $0.1(1)$ & 0.723 \\
Genotype (HiHi, HiLo, LoLo) & $1.4(2)$ & 0.247 \\
Gender $\times$ Genotype interaction term & $4.7(2)$ & 0.013 \\
\hline
\end{tabular}

Note: Results are from type 3 sums of squares

in nondepressed individuals has not been a focus of prior research. Prior to examination of moderating factors, our initial findings in the present sample suggest that TRP infusion results in increased negative emotion in healthy subjects. Similarly, a study of TRP infusion that included a healthy control group (Price et al. 1991) reported that control subjects were less happy, talkative, and energetic following infusion. Others have demonstrated increases in tiredness or drowsiness following TRP infusion in healthy controls (Cowen and Charig 1987; Heninger et al. 1984). Finally, TRP infusion was associated with increased feelings of anger, depression, tension, and fatigue in a sample of healthy controls and nondepressed subjects with a firstdegree relative with bipolar disorder (Sobczak et al. 2003). Thus, the present findings concur with those previously reported in nondepressed subjects, suggesting that the acute infusion of TRP in healthy individuals leads to a general pattern of increased negative emotional responding. Additionally, the current study goes a step beyond prior research in this area by including examination of gender and genotype.

The present results also complement findings from other research evaluating effects of chronic stress on depressive symptoms that suggest that 5-HTTLPR allelic variation may have an opposite effect on depressive symptoms in chronically stressed men and women. Specifically, in
Fig. 1 Day-2 active tryptophan infusion: means for pre-infusion and post-infusion ratings of depression-dejection by genotype and gender
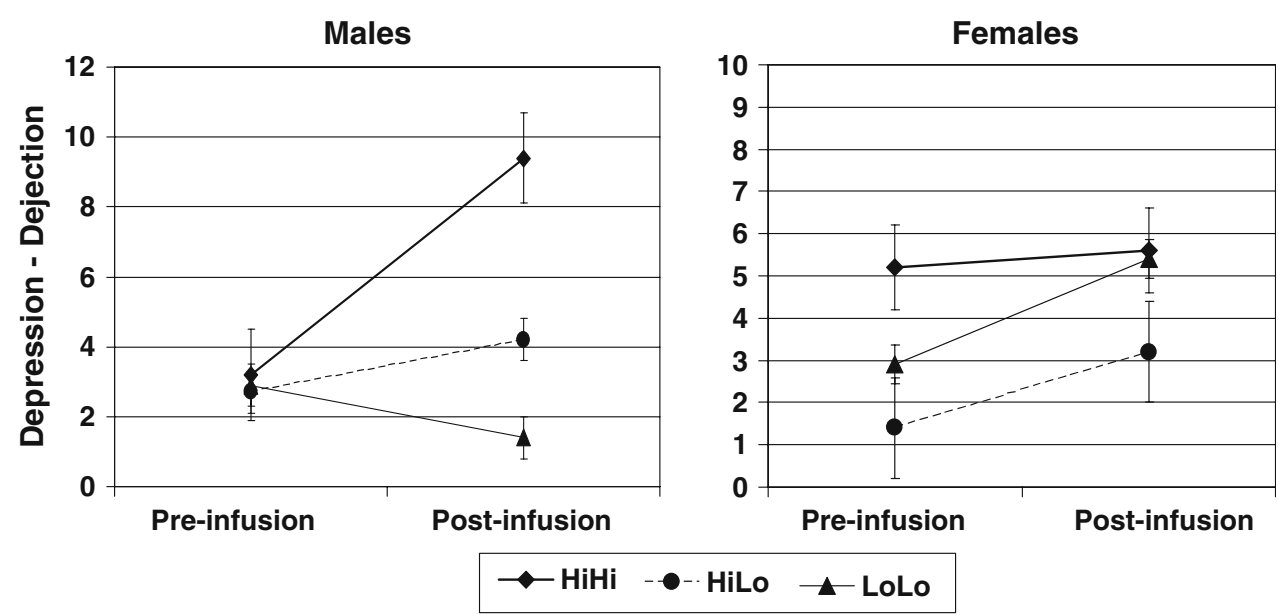
chronically stressed males the presence of the $\mathrm{L}$ allele is associated with negative behavioral traits such as symptoms of depression, whereas, in chronically stressed females it is the $\mathrm{S}$ allele that is associated with increased symptoms of depression (Brummett et al. 2008, 2003; Eley et al. 2004; Flory et al. 1999; Gonda et al. 2005; Jacobs et al. 2006; Sjoberg et al. 2006). The current results parallel these findings by showing that acutely increasing TRP levels increases negative affect in males with 5-HTTLPR alleles associated with the highest level of serotonin transporter transcription, while in females TRP infusion increased negative affect, but only for those with 5-HTTLPR alleles associated with the lowest levels of serotonin transporter transcription. Prior research has documented that acute stress causes an increase in 5-HT release in the CNS (Chaouloff 1993). Changes in negative mood following the pharmacological enhancement of extra-cellular CNS 5-HT by TRP infusion may be similar to those changes that accompany psychological stress in daily life. Thus, these findings suggest that the present gender differences in 5-HTTLPR moderation of mood responses to acute enhancement of CNS 5-HT neurotransmission could be analogous to a similar effect in several chronically stressed samples. That is, higher levels of depressed symptoms reported in chronically stressed men with L/L genotype and in women with S/S genotype could be caused by the accumulation of repeated effects of acute stress to increase CNS serotonin activity, c.f. (Dunn 1998), which then engenders acute increases in depressed mood in men with high expressing 5-HTTLPR alleles and in women with low expressing alleles.

Currently sex differences in serotonergic function are not well understood. Ovarian steroid modulation of serotonergic function may play an important role in gender differences seen in CNS serotonin function-especially those that may influence depressive symptoms - as ovarian steroids clearly affect serotonin synthesis, its removal from the synapse, its metabolism and also its stimulation of pre and postsynaptic receptor populations (Bethea et al. 2002; Gundlah et al. 2002; Lu and Bethea 2002; Pecins-Thompson and Bethea 1999; Smith et al. 2004). It seems transporter expression, as influenced by 5-HTTLPR genotype, may also play a critical role in the association we report here between sex and negative affective responses. In 5-HT1 $1_{\mathrm{b}}$ knockout mice, females exhibit greater disinhibition of serotonin release which manifests as less depressive behavior than $5 \mathrm{HT}^{\mathrm{b}}$ knockout males. These findings suggest that the presynaptic $5-\mathrm{HT} 1_{\mathrm{b}}$ autoreceptors contribute differentially to regulation of extracellular serotonin in intact females and intact males. The observed changes in the present study suggest that there is either a different balance of reuptake, synthesis, and receptor sensitivity controlling serotonergic tone in men and women; or that the promoter polymorphisms are not directly controlling 5-HT expression in adulthood, but influence the development of the serotonin system in a gender-specific way. Gender influence on regulation of release, reuptake, and receptor sensitivity likely coordinate in a complex way to control extracellular serotonin in men and women; thus the critical test would include a valid measure of extracellular serotonin.

Certain limitations should be noted with respect to the present findings. The sample in this experiment consisted of only 72 participants, thus all results should be interpreted with proper caution. Replication in additional samples will be required in order to determine their validity. The lack of a stronger relation in the opposite direction for females may have been due to lack of adequate power, which is a particularly important issue to be considered when examining models that contain interactions. In addition, we were unable to examine ethnicity as a further moderator due to insufficient numbers of participants in certain cells.

The present findings contribute to a large body of prior work indicating that the CNS serotonin system behaves differently in men and women in many important ways (Biver et al. 1996; Costes et al. 2005; Jonsson et al. 2000; Kornstein et al. 2000; Nishizawa et al. 1997; Williams et al. 2003). More specifically, the current results corroborate recent findings indicating that the presence of the more high expressing allele of the 5-HTTLPR polymorphism may place chronically stressed males at higher risk for depressive symptoms. They also suggest a mechanism whereby acute increases in depressive mood engendered by stress-induced acute increases in CNS 5-HT activity may, over time, lead to increased sustained depressive symptom levels in males with the more high expressing alleles, with a similar mechanism accounting for high depressive mood levels in chronically stressed women with low expressing alleles. It is likely that continued converging results from related areas of research that use both experimental and epidemiological approaches will provide insight into the ways in which sex differences in serotonergic functioning impact emotional, as well as physical health, for both men and women.

Acknowledgments This research was supported by the National Heart, Lung, and Blood Institutes grant 3P01 HL036587; the National Institutes of Mental Health grant R01MH57663; the National Institute on Aging grant R01AG19605, with co-funding by National Institute of Environmental Health Sciences; and by the Clinical Research Unit grant M01RR301.

\section{References}

Bethea CL, Mirkes SJ, Su A, Michelson D (2002) Effects of oral estrogen, raloxifene and arzoxifene on gene expression in serotonin neurons of macaques. Psychoneuroendocrinology 27:431-445. doi:10.1016/S0306-4530(01)00054-3 
Biver F, Lotstra F, Monclus M, Wikler D, Damhaut P, Mendlewicz J et al (1996) Sex difference in 5HT2 receptor in the living human brain. Neurosci Lett 204:25-28. doi:10.1016/0304-3940(96) 12307-7

Brummett BH, Siegler IC, McQuoid DR, Svenson IK, Marchuk DA, Steffens DC (2003) Associations among the NEO Personality Inventory, Revised and the serotonin transporter gene-linked polymorphic region in elders: effects of depression and gender. Psychiatr Genet 13:13-18. doi:10.1097/00041444-20030300000002

Brummett BH, Boyle SH, Siegler IC, Kuhn C, Ashley-Koch A, Jonassaint CR et al (2008) Effects of environmental stress and gender on associations among symptoms of depression and the serotonin transporter gene linked polymorphic region (5-HTTLPR). Behav Genet 38:34-43. doi:10.1007/s10519-0079172-1

Burroughs AR, Visscher AW, Haney TL, Efland JR, Barefoot JC, Williams RB et al (2003) Community recruitment process by race, gender, and ses gradient: lessons learned from the community health and stress evaluation (chase) study experience. J Community Health 28:421-437. doi:10.1023/A:1026 029723762

Chaouloff F (1993) Physiopharmacological interactions between stress hormones and central serotonergic systems. Brain Res Brain Res Rev 18:1-32. doi:10.1016/0165-0173(93)90005-K

Checkley SA (1980) Neuroendocrine tests of monoamine function in man: a review of basic theory and its application to the study of depressive illness. Psychol Med 10:35-53

Cleare AJ, Bond AJ (1995) The effect of tryptophan depletion and enhancement on subjective and behavioural aggression in normal male subjects. Psychopharmacology 118:72-81. doi:10.1007/ BF02245252

Cleare AJ, Bond AJ (1997) Does central serotonergic function correlate inversely with aggression? A study using D-fenfluramine in healthy subjects. Psychiatry Res 69:89-95. doi: 10.1016/S0165-1781(96)03052-1

Coccaro EF (1992) Impulsive aggression and central serotonergic system function in humans: an example of a dimensional brainbehavior relationship. Int Clin Psychopharmacol 7:3-12. doi: 10.1097/00004850-199200710-00001

Coccaro EJ, Seiver JL, Klar HM, Maurer G, Cochrane K, Cooper TB et al (1989) Serotonergic studies in patients with affective and personality disorders. Arch Gen Psychiatry 46:587-599

Costes N, Merlet I, Ostrowsky K, Faillenot I, Lavenne F, Zimmer L et al (2005) An 18F-MPPF Pet normative database of 5-HT1a receptor binding in men and women over aging. J Nucl Med 46:1980-1989

Cowen PJ, Charig EM (1987) Neuroendocrine responses to intravenous tryptophan in major depression. Arch Gen Psychiatry 44:958-966

Du I, Bakish D, Hrdina PD (2000) Gender differences in association between serotonin transporter gene polymorphism and personality traits. Psychiatr Genet 10:159-164

Dunn AJ (1998) Brain catecholamine and tryptophan responses to restraint are attenuated by nitric oxide synthase inhibition. Neurochem Int 33:551-557. doi:10.1016/S0197-0186(98) 00064-3

Eley TC, Sugden K, Corsico A, Gregory AM, Sham P, McGuffin P et al (2004) Gene-environment interaction analysis of serotonin system markers with adolescent depression. Mol Psychiatry 9:908-915. doi:10.1038/sj.mp.4001546

Flory JD, Manuck SB, Ferrell RE, Dent KM, Peters DG, Muldoon MF (1999) Neuroticism is not associated with the serotonin transporter (5-HTTLPR) polymorphism. Mol Psychiatry 4:93-96. doi:10.1038/sj.mp.4000466

Gelernter J, Kranzler H, Caccaro EF, Siever LJ, New AS (1998) Serotonin transporter protein gene polymorphism and personality measures in African American and European American subjects. Am J Psychiatry 155:1332-1338

Gonda X, Juhasz G, Laszik A, Rihmer Z, Bagdy G (2005) Subthreshold depression is linked to the functional polymorphism of the 5HT transporter gene. J Affect Disord 87:291-297. doi:10.1016/j.jad.2005.05.007

Gundlah C, Lu NZ, Betha CL (2002) Ovarian steroid regulation of monoamine oxidase-A and $\mathrm{B}$ mRNAs in the macaque dorsal raphe and hypothalamic nuclei. Psychopharmacology 160:271282. doi:10.1007/s00213-001-0959-0

Heninger GR, Charney DS, Sternberg DE (1984) Serotonergic function in depression. Prolactin response to intravenous tryptophan in depressed patients and healthy subjects. Arch Gen Psychiatry 41:398-402

Hu XZ, Lipsky RH, Zhu G, Akhtar LA, Traubman J, Greenberg BD et al (2006) Serotonin transporter promoter gain-of-function genotypes are linked to obsessive-compulsive disorder. Am J Hum Genet 78:815-826. doi:10.1086/503850

Jacobs N, Kenis G, Peeters F, Derom C, Vlietinck R, van OS J (2006) Stress-related negative affectivity and genetically altered serotonin transporter function. Arch Gen Psychiatry 63:989-996. doi:10.1001/archpsyc.63.9.989

Jonsson EG, Norton N, Gustavsson P, Oreland L, Owen MJ, Sedvall GC (2000) A promoter polymorphism in the monoamine oxidase A gene and its relationships to monoamine metabolite concentrations in CSF of healthy volunteers. J Psychiatr Res 34:239244. doi:10.1016/S0022-3956(00)00013-3

Knapp TR, Kimble LP, Dunbar SB (1998) Distinguishing between the stability of a construct and the stability of an instrument in trait/ state measurement. Nurs Res 47:60-62. doi:10.1097/00006199199801000-00011

Kornstein SG, Schatzberg AF, Thase ME, Yonkers KA, McCullough JP, Keitner GI et al (2000) Gender differences in treatment response to sertraline versus imipramine in chronic depression. Am J Psychiatry 157:1445-1452. doi:10.1176/appi.ajp.157.9.1445

Lu NZ, Bethea CL (2002) Ovarian steroid regulation of 5-HT1a receptor binding and $\mathrm{G}$ protein activation in female onkeys. Neuropsychopharmacology 27:21-24

Manuck SB, Flory JD, McCaffery JM, Matthews KA, Mann JJ, Muldoon MF (1998) Aggression, impulsivity, and central nervous system serotonergic responsivity in a nonpatient sample. Neuropsychopharmacology 19:287-299

Marsh DM, Dougherty DM, Moeller FG, Swann AC, Spiga R (2002) Laboratory-measured aggressive behavior of women: acute tryptophan depletion and augmentation. Neuropscyhopharmacology 26:660-671. doi:10.1016/S0893-133X(01)00369-4

McNair DM, Lorr M (1964) An analysis of mood in neurotics. J Abnorm Soc Psychol 69:620-627. doi:10.1037/h0040902

Moeller FG, Seteinberg JL, Petty F, Fulton M, Cherek DR, Dramer G et al (1994) Serotonin and impulsive/aggressive behavior in cocain dependent subjects. Prog Neuropsychopharmacol Biol Psychiatry 18:1027-1035. doi:10.1016/0278-5846(94)90128-7

Nishizawa S, Benkelfat C, Young SN, Leyton M, Mzengeza S, de Montigny C et al (1997) Differences between males and females in rates of serotonin synthesis in human brain. Proc Natl Acad Sci USA 94:4823-4824. doi:10.1073/pnas.94.10.5308

O'Keane VO, Moloney E, O'Neill H, O'Connor A, Smith R, Dian TG (1992) Blunted prolactin responses to d-Fenfluramine in sociopathy: evidence for subsensitivity of central serotonergic function. Br J Psychiatry 160:643-646

Pecins-Thompson M, Bethea CL (1999) Ovarian steroid regulation of serotonin-1A autoreceptor messenger rna expression in the dorsal raphe of rhesus macaques. Neuroscience 89:267-277. doi: 10.1016/S0306-4522(98)00326-1

Price LH, Charney DS, Delgado PL, Goodman WK, Krystal JH, Woods SW et al (1990) Clinical studies of 5-Ht Function using 
i.v. L-tryptophan. Prog Neuropsychopharmacol Biol Psychiatry 14:459-472. doi:10.1016/0278-5846(90)90002-X

Price LH, Charney DS, Delgado PL, Heninger GR (1991) Serotonin function and depression: neuroendocrine and mood responses to intravenous 1-tryptophan in depressed patients and healthy comparison subjects. Am J Psychiatry 148:1518-1525

Richell RA, Deakin JFW, Anderson IM (2005) Effect of acute tryptophan depletion on the response to controllable and uncontrollable noise stress. Biol Psychiatry 57:295-300. doi: 10.1016/j.biopsych.2004.10.010

Sjoberg RL, Nilsson KW, Nordquist N, Ohrvik J, Leppert J, Lindstrom L et al (2006) Development of depression: sex and the interaction between environment and a promoter polymorphism of the serotonin transporter gene. Int J Neuropsychopharmacol 9:443449. doi:10.1017/S1461145705005936

Smith LJ, Henderson JA, Abell CW, Bethea CL (2004) Effects of ovarian steroids and raloxifene on proteins that synthesize, transport and degrade serotonin in the raphe region of macaques. Neuropsychopharmacology 29:2035-2045. doi:10.1038/sj.npp. 1300510

Sobczak S, Honig A, Schmitt JAJ, Riedel WJ (2003) Pronounced cognitive deficits following an intravenous L-Tryptophan challenge in first-degree relatives of bipolar patients compared to healthy controls. Neuropscyhopharmacology 28:711-719. doi: 10.1038/sj.npp.1300055

Surtees PG, Wainwright NWJ, Willis-Owne SAG, Luben R, Day NE, Flint J (2006) Social adversity, the serotonin transporter (5-HTTLPR) polymorphism and major depressive disorder. Biol Psychiatry 59(3):224-229

Van der Does AJW (2001) The effects of tryptophan depletion on mood and psychiatric symptoms. J Affect Disord 64:107-119. doi:10.1016/S0165-0327(00)00209-3

Williams RB, Marchuk DA, Gadde KM, Barefoot JC, Grichnik K, Helms MJ et al (2001) Central nervous system serotonin function and cardiovascular responses to stress. Psychosom Med 63:300305

Williams RB, Marchuk DA, Gadde KM, Barefoot JC, Grichnik K, Helms MJ et al (2003) Serotonin-related gene polymorphisms and central nervous system serotonin function. Neuropsychopharmacology 28:533-541. doi:10.1038/sj.npp.1300054

Yatham LN, Steiner M (1993) Neuroendocrine probes of serotonergic function: a critical review. Life Sci 53:447-463. doi:10.1016/ 0024-3205(93)90696-Z 